УДК 130.12

DOI: 10.18101/1994-0866-2019-2-12-19

\title{
НОМО LOGUENS И ПРОЦЕССЫ ЭТНИЧЕСКОЙ ИДЕНТИФИКАЦИИ
}

\author{
(C) Истомина Ольга Борисовна \\ доктор философских наук, профессор, \\ заведующая кафедрой социально-экономических дисциплин, \\ Иркутский государственный университет \\ Россия, 664011, г. Иркутск, ул. Сухэ-Батора, 9 \\ E-mail: olgaistomina@mail.ru
}

\section{(C) Томских Евгения Олеговна}

старший лаборант,

Иркутский государственный университет

Россия, 664011, г. Иркутск, ул. Сухэ-Батора, 9

E-mail: sotcek@mail.ru

В статье авторы анализируют функции и возможности языка в процессах социальной идентификации индивида. Язык как маркер всего социокультурного поведения участвует в определении этнической ингруппы. Эта функция языка актуализируется в поликультурном социальном окружении. Иноязычная среда определяет особую значимость этноконсолидирующей функции языка. Лингвокультурные контакты в полиэтническом регионе одновременно являются формой диалога культур; «социальным зеркалом», обеспечивающим выявление специфических черт культуры собственной этногруппы; средством интеракции, которое позволяет провести рефлексивное проектирование самости культуры; фактором этноконсолидации; условием развития кросс-культурной компетентности. Взаимодействие языков на общей территории есть действие диспозиции «свой язык - иной язык», которая формирует автостереотипы и способствует осознанию гетеростереотипов этногруппы. Данные выводы построены на результатах авторских исследований критериев определения родного языка респондентами, проживающими в Иркутской области (2011-2018). Несмотря на объективное распространение инструменталистского подхода в философии языка, не меньшее значение в современных условиях имеет философскокультурологический подход, который рассматривает язык как единство эмоционально-оценочного, сенсорно-рецептивного, логико-понятийного, ценностнонравственного компонентов обыденного сознания носителя языка. Приоритетность философского понимания языка приписывает этничности значение коммуникативного ресурса, определяющего не только речевое, но и социальное поведение. Язык является доминирующим фактором в системе этнической идентификации индивида.

Ключевые слова: язык; языковая личность; языковые контакты; коммуникативное поведение; этническая идентификация; социальное взаимодействие.

\section{Для цитирования:}

Истомина О. Б., Томских Е. О. Ноmo loguens и процессы этнической идентификации // Вестник Бурятского государственного университета. Философия. 2019. Вып. 2. С. 12-19.

Homo loguens, или языковая личность, есть социальное зеркало всех социокультурных процессов текущей реальности. Роль языка в современном поликультурном пространстве значительна. В межэтнических коммуникациях язык является социокультурным маркером, средством не только этноидентификации, 
но и самоопределения в широком поле культурного многообразия. В условиях преобладания процессов глобализации и противостоящей ей глокализации язык для этногруппы является доминирующим фактором как самокатегоризации, так и сохранения и развития этнической культуры в целом. Ситуация расширения функционального поля мажоритарного языка (а в российском коммуникативном пространстве объективно таковым является русский язык) определяет сужение сфер этнического дискурса, его смещение в семейно-бытовую сферу и, как следствие, ассимиляцию этнических языков. Данные деструктивные процессы обусловливают девальвацию этнических языков, а значит, негативно сказываются на культуре этногруппы в целом. Язык, являясь, по выражению М. Хайдеггера, «домом бытия», максимально долго сохраняет нарративное содержание культуры и создает условия для успешной социализации homo loguens [4]. В этом видятся культурная ценность языка и его этноконсолидирующие потенции. Ното loguens - это выражение коммуникативного поведения индивида, в котором аккумулированы история народа, его мифология и нарративные ценности, историческое прошлое, морально-нравственные ориентиры, духовные и мировоззренческие связи, специфические черты культуры, религиозные верования, обычаи, традиции, социальные нормы и диспозиции, нормы бытоустройства, что определяет содержание языковой картины мира, ее онтологические, гносеологические, аксиологические основания.

Поселенческая структура большей части российских регионов характеризуется высокой дисперсностью расселения этногрупп, различными степенями мозаичности этнонациональной структуры, что обусловливает разность типов этнической идентификации: от этнофанатизма до этнической индифферентности. В условиях нарастания гена конфликтности во внешне- и внутриполитических отношениях важно сохранить сложившиеся во многих регионах тенденции доминирования позитивной идентичности. К таким регионам относится Иркутская область, где этнонациональная структура по численности групп тождественна общероссийской структуре. Численно доминируют в названном регионе русские $(88,3 \%)$, украинцы $(1,2 \%)$, буряты $(3,2 \%)$, татары $(0,9 \%)$, другие $(6,4 \%)$. На территории области проживает более 140 этногрупп, при этом индекс мозаичности национального состава и сопряженная с ним интенсивность межэтнических контактов характеризуются низкими показателями в силу численной диспропорции этногрупп (на основании данных Всероссийской переписи населения 2010 г. индекс составляет 0,1). Данные показатели рассчитаны по методике М. С. Джунусова [12]. Однако в регионе исторически сформировались поселения с высоким индексом, где проживает несколько этногрупп, приблизительно равных в численном отношении, что увеличивает интенсивность контактов. К таковым следует отнести Усть-Ордынский Бурятский округ (индекс составляет 0,6), татарское село Тараса, польское поселение Вершины и др. Исторически сложившийся в регионе тип позитивной этноидентификации определяет важность данного процесса в системе межэтнических контактов и обеспечивает бесконфликтность взаимодействия этногрупп [14]. Тем не менее проблемы существуют. На наш взгляд, в регионе с дисперсным и разнородным типом расселения этногрупп важно сохранить бесконфликтный характер культурных связей, что напрямую зависит от типа лингвокультурных контактов, принятых в регионе, от социокультурных привычек и мировоззренческих связей, реализуемых homo loguens в 
их повседневном дискурсе [1]. Данные связи и отношение к собственной этнической культуре в целом обусловлены отношением к родному языку, его пониманием и восприятием, оценкой его роли в индивидуальной и культурной картине мира. Авторами проведено исследование динамики оценок содержания понятия «родной язык» экспертной группой области.

Целью данного исследования является определение роли языка в системе этноидентификации языковой личности в поликультурной среде. Авторами использовались диалектический и компаративный методы, структурнофункциональный анализ. Также использовался метод конкретного социологического исследования: экспертные опросы «Критерии определения родного языка», проведенные авторами в 2011-2018 гг. Общий объем выборки - 82 респондента (2011), 98 опрошенных (2018). Экспертную фокус-группу на каждом этапе исследования с целью определения динамики дефиниции родного языка составили преподаватели и студенты-выпускники филологического факультета Иркутского государственного университета. Анкета, составленная авторами, содержит наиболее востребованные критерии, условно поделенные на три группы: инструменталистская (важны активность употребления языка и его функциональная нагрузка), философско-культурологическая (язык понимается как базовый компонент культуры) и группа самостоятельного выбора (по самоопределению респондента). Для определения индекса мозаичности национального состава исследуемого региона в качестве информационной базы послужили данные Bceроссийской переписи населения 2010 г.

Амбивалентность оценок языка и его функций в современных условиях проявляется в стандартизации мировоззрения общества (влияние глобализационных процессов) и в актуализации идентификационной и консолидирующей функций языков этногрупп в поликультурном пространстве (явление глокализации и ревитализации этнического самосознания).

Современная философия языка представлена теориями двух масштабных подходов: философско-культурологического и инструменталистского.

Философско-культурологический подход представлен в работах Н. Д. Арутюновой [7], Й. Л. Вайсгербера [9], В. Гумбольдта [11], Л. М. Дробижевой [13], Н. Б. Мечковской [15], М. Мюллера, Э. Сепира, Б. Уорфа [16], Т. Ю. Тамеряна [19], Г. Тэшфела, Дж. Тернера [6]. По справедливому замечанию Ж. Т. Тощенко, язык - это «своеобразный политико-психологический тезаурус, позволяющий единообразно воспринимать окружающую реальность, оценивать ее и действовать в ней в соответствии с определенными, устоявшимися в социальной общности нормами и образами поведения, адекватно воспринимая и понимая при этом друг друга» [20]. Философское толкование языка и родного для этногруппы языка напрямую связано с ее мировоззрением, совокупностью суждений о человеке, мире и их взаимодействии. В рамках данного подхода язык мыслится как своего рода рефлексия (или метатеория) содержания социальной системы, ее трансформации, динамики ценностно-мотивационной базы сознания, как следствие, самоперцепции, отражение автостереотипов. А. Б. Панькин называет язык «основным показателем личностного и национального самосознания, важнейшим структурным элементом культуры народа, основой развития его интеллекта, эмоциональной сферы, творческого потенциала, залогом межнационального воспитания молодежи» $[17$, с. 14$]$. На основании данного подхода сформировано понятие «язы- 
ковая картина мира», в ней зафиксированы особенности ментальности народа, его культура как «комплекс, включающий знания, верования, искусство, мораль, законы, обычаи, а также иные способности и навыки, усвоенные человеком как членом общества» [18]. По мнению Л. Витгенштейна, реальность опосредуется языком, который создает образ мира: «Границы моего языка определяют границы моего мира» [10]. Сообразно данным дефинициям, lingua ethos - это «лигвокод культуры».

В противовес философскому подходу в рамках процессов универсализации культуры трансформируется понимание языка в сторону прагматизации смыслов, когда функциональная нагруженность и ротационные характеристики языка обретают доминирующее положение в семантике понятия «родной язык». Следствием распространения инструменталистского подхода можно признать востребованность критерия «функциональная первичность и частота употребления» в общем объеме идентификаций родного языка его носителями. Данный подход популяризирует утилитарные задачи языка, его потенции в практическом применении в конкретных социальных стратегиях. Таким образом, инструменталистский подход ориентирован на достижение узкопрагматических прикладных целей дискурса.

Тем не менее, несмотря на разность определяющих позиций, обозначенные подходы не являются в своем крайнем выражении антагонистами. На наш взгляд, напротив, их диспозиционность выражает взаимодополняемость и целостность в совокупности. Интеграция философского и инструментального подходов как синтез объективной и субъективной позиций определения семантического поля понятия «родной язык» позволяет сохранить понимание культурной значимости и ценности языка при изменении его функциональной нагрузки. Очевидно, что инструменталистский подход в отдельности, невзирая на свою рациональность и прагматичность, существенно обедняет мировоззренческие позиции носителя языка, умаляет роль миноритарных языков, способствует разрушению этнического самосознания, распространению ассимиляционных процессов.

В ситуации распространения аккультурационных механизмов межкультурного взаимодействия и сведения родного языка к примитивному инструменту решения коммуникативных задач повышаются риски эрозии этнокультурного разнообразия. Данные условия девальвируют этнический критерий в системе идентификаций и переориентируют индивида на общемировое культурное пространство с мажоритарным языком.

В результате исследований приоритетности критериев определения родного языка, проведенных авторами в 2011-2018 гг. в Иркутской области, выявлено постепенное смещение позиций философско-культурологического подхода в сторону инструментализма. Трансформации в дефиниции родного языка, на наш взгляд, обусловлены преобладанием прагматических задач в коммуникативном процессе с доминированием во всех сферах общения мажоритарного языка (численно доминирующей в регионе этногруппы) как средства успешной социализации. В ходе опроса эксперты самостоятельно определяли значимость критерия в процессе самоидентификации, оценивая степень важности по принципу 1 - самое важное, 7 - наименее важное из перечисленного. По данным анкеты посчитан средний балл, отражающий позицию критерия в рейтинге. Исчисления балла построены на сумме цифр, определяющих каждый критерий отдельно и делени- 
ем полученной суммы на общее число респондентов. Чем ниже средний балл критерия, тем выше его степень значимости в сознании респондента. Результаты экспертного опроса отражены в таблице 1.

Таблииа 1

Критерии определения дефиниции «родной язык»

\begin{tabular}{|l|l|c|c|}
\hline \multirow{2}{*}{ № } & \multicolumn{1}{|c|}{ Родной язык - это... } & \multicolumn{2}{|c|}{ Средний балл } \\
\cline { 3 - 4 } & \multicolumn{1}{|c|}{$\mathbf{2 0 1 1}$} & $\mathbf{2 0 1 8}$ \\
\hline 1 & язык моей матери, язык, на котором говорят в моей семье & 2,3 & 2,4 \\
\hline 2 & язык, который я усвоил первым & 4,1 & 3,7 \\
\hline 3 & язык моего народа, моей национальной принадлежности & 1,9 & 2,1 \\
\hline 4 & язык, которым я владею лучше всего & 4,6 & 3,9 \\
\hline 5 & $\begin{array}{l}\text { язык, который является в моей жизни функционально пер- } \\
\text { вым, которым я пользуюсь чаще всего }\end{array}$ & 3,7 & 2,9 \\
\hline 6 & язык, на котором я думаю & 2,9 & 2,5 \\
\hline 7 & язык, который я по собственному желанию считаю таковым & 5,5 & 5,4 \\
\hline 8 & другой вариант & 4 & 5 \\
\hline
\end{tabular}

В течение семилетнего периода наиболее значимым остается критерий национальной принадлежности (критерий 3), на втором месте - критерий функциональности в семье (критерий 1), на третьем - критерий функциональности в речи самого респондента (критерий 5) и в процессе речепорождения как когнитивного акта (критерий 6). Результаты опроса выявляют амбивалентность идентификации, выраженной в признании фокус-группой как философского, так и инструментального подходов к дефиниции языка. Значимость ротационных характеристик языка в общем объеме дискурса выявлена в молодежной группе респондентов (21-23 лет) - 14,6\%. Для старшего возраста язык является лингвокодом культуры, выполняющим роль средства интеракции, обеспечивающим, по выражению А. Гидденса, «рефлексивное проектирование самости» [2]. Иными словами, для респондентов старшей возрастной группы «язык является символом этнической идентичности, а языковой выбор - символом этнических отношений» [5, с. 308], поэтому критерии функциональной группы актуальны только для 2,4\% экспертов 45-60 лет.

Повторное исследование в 2018 г. выявило нарастание тенденций инструментализма в отношении родного языка. В регионах с дисперсным и разнородным типом расселения этногрупп, каким является Прибайкалье, сохранение мозаичности этнокультурной структуры важно для развития бесконфликтных культурных связей. В поликультурной среде язык тождественен культуре этногруппы в целом, а его сохранность - признак сохранности этноса. Нельзя не согласиться с Г. Джайлсом, нет языка - нет народа, язык определяет «этнолингвистическую жизнеспособность этноса» [3]. Ревитализация языков этнических групп поликультурного региона определяет развитие лингвокультурных контактов, реминисценций. Лингвоконтактность играет роль «культурного зеркала». В условиях диспозиции «свой - чужой» лингвокультура обнаруживает свою специфику, выявляет базовые отличия, обнаруживает самобытность, уникальность культуры. Только в диалоге можно обнаружить себя, понять себя более глубоко. Как писал М. М. Бахтин, «мы ставим чужой культуре новые вопросы, каких она сама себе не ставила, мы ищем у нее ответы на эти вопросы; и чужая культура отвечает 
нам, открывая перед нами новые свои стороны, новые смысловые глубины» [8, c. 335]. На основе диалога культур формируется кросс-культурная компетентность акторов. Взаимодействие лингвокультур готовит сознание реципиентов к восприятию иного окружения, к толерантному отношению культурных отличий, что является условием этнонационального равновесия в полиэтническом пространстве, учит коммуникантов успешно функционировать в разнообразных социокультурных контекстах, достигать цели эффективного социального взаимодействия [14].

Способность понимать и ценить свою культуру напрямую связана с готовностью к восприятию иных культурных образований, с открытостью к диалогу. Диалогичность культуры благодаря компаративным процедурам позволяет группе самоидентифицироваться, через социальное зеркало узнать самое себя.

Итак, язык в системе этнической идентификации имеет фундаментальное значение, его роль в процессе социализации и инкультурации индивида первостепенна. Мышление и язык, будучи взаимосвязанными и взаимозависимыми компонентами сознания, формируют языковую картину мира, в которой заключается весь нарратив, весь социокультурный опыт этногруппы. Этничность выступает в индивидуальном самосознании ресурсом, обеспечивающим не только коммуникативное, но и социальное поведение в целом. Этничность определяет социально-бытовые привычки, основы мироощущения, самооценку, основы жизнедеятельности, определяет лонгитюдные и краткосрочные социальные стратегии в соответствии с требованиями общественной среды.

Дифференцирующим признаком этноса, его самоперцепции, объективной и пространственно-временной, мотивационной, нормативной ориентации согласно философско-культурологическому подходу, взятому за основу данного исследования, является язык как лингвокультурный код этнической группы.

В результате проведенных экспертных опросов выявлены динамика дефиниции «родной язык», амбивалентность определения данного понятия, актуализация инструменталистского подхода в молодежной социальной группе и доминирование философского понимания lingua ethos у респондентов старшего поколения. Прагматизация дискурса и определение языка только как инструмента в решении узкоутилитарных практических задач существенно сужают пространство этнических языков, определяют распространение тенденций унификации и универсализации культуры, что детерминирует эрозию этнического сознания и языковую ассимиляцию. Философская трактовка языка способствует сохранению и ревитализации культурного разнообразия в многонациональных государствах, подчеркивает важность языковых контактов, диалога культур для более глубокого погружения в собственную культуру и толерантного отношения к инокультурному окружению: «...лишь соприкосновение одного языка с другим на почве сравнений - как одна и та же мысль в разных языках по-разному выражена естественным образом останавливает на средствах выражения и делает человека внимательным к тонким нюансам мысли и чувства; приучает человека не скользить по привычным явлениям родного языка, а подмечать разные оттенки мысли, до сих пор не замеченные в родном языке» [21, с. 53].

Диалог метафор, достигаемый через лингвокультурные контакты, способствует объективации культуры в целом и индивидуального восприятия, обога- 
щению картины мира, укоренению в сознании позитивного типа самокатегоризации и бесконфликтных типов межэтнического и межнационального общения.

\author{
Литература \\ $284 \mathrm{p}$. \\ 1. Agar M. H. Language shock: Understanding the culture of conversation. N. Y., 1994.
}

2. Giddens A. Modernity and self identity: Self and society in the late modern age. Stanford, 1991. P. 187-201.

3. Giles H., Bourhis R. Y., Taylor D. M. Towards a theory of language in ethnic group relation // Language, ethnicity and intergroup relations. L.: Acad. Press, 1977. P. 307-348.

4. Heidegger Martin. Sein und Zeit. Max Niemeyer Verlag, 2002. 445 s.

5. Heller M. Language, ethnicity and politics in Quebec. Berkeley, 1982. P. 308.

6. Tajfel H., Turner J. C. The social identitytheory ofintergroup behavior // Psychology of intergroup relations. Chicago: Nelson-Hall, 1986. P. 7-24.

7. Арутюнова Н. Д. Язык и мир человека. М., 1999. 896 с.

8. Бахтин М. М. Этика словесного творчества. М., 1986. С. 335.

9. Вайсгербер Й. Л. Родной язык и формирование духа. М., 2004. 232 с.

10. Витгенштейн Л. Избранные работы. М.: Территория будущего, 2005. 440 с.

11. Гумбольдт В. фон. Избранные труды по языкознанию. М., 2000. 400 с.

12. Джунусов М. С. Сближение советских национальных культур и развитие общенародного двуязычия // Национальный язык и национальная культура. М., 1978. С. 145-162.

13.Дробижева Л. М. Социальные проблемы межнациональных отношений в постсоветский период. М., 2003. 376 с.

14. Истомина О. Б. Языковые контакты в современном российском обществе: сущность, формы, тенденции (региональный аспект) / науч. ред. И. И. Осинский. Улан-Удэ: Изд-во Бурят. гос. ун-та, 2012. 288 с.

15. Мечковская Н. Б. Социальная лингвистика. М., 2000. 2007 с.

16. Мюллер М., Сепир Э., Уорф Б. Витгенштейн. Языки как образ мира. М.: АСТ, СПб.: Terra Fantastica, 2003. 576 c.

17. Панькин А. Б. Этнокультурная коннотация образования. Элиста, 2009. С. 14.

18. Тайлор Э. Б. Первобытная культура. М., 1989. 573 с.

19. Тамерян Т. Ю. Модель мира в языке: проблемы двуязычного пространства. Владикавказ, 2004. 218 с.

20. Тощенко Ж. Т. Этнократия: История и современность. Социологические очерки. M., 2003. C. 407.

21. Щерба Л. В. Преподавание иностранных языков в средней школе. М., 1974. С. 53.

\title{
HOMO LOGUENS AND ETHNIC IDENTIFICATION PROCESSES
}

\section{Olga B. Istomina}

Dr. Sci. (Philos.), Prof., Head of Department of Social and Economic Disciplines, Pedagogical Institute, Irkutsk State University

9 Sukhe-Batora St., Irkutsk 664011, Russia

E-mail: olgaistomina@mail.ru

Evgeniya O. Tomskikh

Senior Assistant,

Pedagogical Institute, Irkutsk State University

9 Sukhe-Batora St., Irkutsk 664011, Russia

E-mail: sotcek@mail.ru 
The article analyzes functions and possibilities of language in the processes of social identification of an individual. Language as a marker of socio-cultural behavior is involved in definition of an ethnic in-group. This function of language is actualized in a multicultural social environment. A foreign-language environment determines the special significance of ethnoconsolidating function of the language. Linguistic and cultural contacts in a multi-ethnic region are simultaneously a form of dialogue of cultures; "social mirror" providing the identification of specific features of the culture of native ethnic group; means of interaction, which allows for the reflexive projecting of culture's sameness; ethnoconsolidating factor; condition for the development of cross-cultural competence. The interaction of languages in a common territory is a manifestation of the disposition "native language - another language", which forms autostereotypes and contributes to the awareness of hetero-stereotypes of the ethnic group. These findings are based on the results of our research aimed at establishing the criteria for determining the native language of respondents living in Irkutsk Oblast (2011-2018). Despite the objective spread of the instrumentalist approach in philosophy of language, the philosophical and culturological approach that considers language as a unity of emotional-value, sensoryreceptive, discursive, value and moral components of the ordinary consciousness of a native speaker has no less significance in modern conditions. The priority of a philosophical understanding of language attributes to ethnicity a value of communicative resource that determines not only verbal, but also social behavior. Language is the dominant factor in the system of ethnic identification of an individual.

Keywords: language; linguistic persona; language contacts; communicative behavior; ethnic identification; social interaction. 